\title{
0 caso de uma comunidade avaliativa emergente: re-apropriação pelos pares-multiplicadores da apreciação
de suas próprias ações preventivas contra DST/HIV/AIDS, Amazonas, Brasil
}

Hélène Laperrière ${ }^{1}$

LAPERRIÈRE, $H$. The case of an emerging evaluative community: peer multipliers' reappropriation of the assessment of their own preventive and social actions against STD/HIV/Aids, Amazonas, Brazil. Interface - Comunic., Saúde, Educ., v.12, n.26, p.527-40, jul./set. 2008.

This paper reports on the systematization of an experience of evaluative and participative investigation relating to a DST/HIV/Aids prevention program that was implemented in the red-light zones of a remote municipality in the State of Amazonas. This perspective of qualitative evaluation emphasized issues that were not considered at the time of initially implementing this project among sex workers, relating to the dimensions of the constructions of collective meaning that were directly linked to the implementation of peer-based education. We have focused on this experience of community investigation with peer multipliers for the project and the reappropriation of the evaluation of their preventive and social actions. The results and discussion are presented as a double prism: 1 the sequence of "emerging" thematic questioning over the course of the participative action/investigation in the field; and 2 the pragmatic practices of the evaluative investigation within the sociocultural and sociopolitical context.

Key words: Community investigation. Evaluation of results from preventive actions. Popular healthcare education. HIV/Aids. Amazonas.
Este artigo relata a sistematização de uma experiência de pesquisa avaliativa e participativa de um projeto de prevenção de DST/HIV/AIDS implantado nas zonas de prostituição de um município do interior do estado do Amazonas. Essa perspectiva de avaliação qualitativa enfatizou aspectos não considerados durante a implantação do projeto inicial, referentes à construção dos significados coletivos diretamente ligados à implantação da chamada educação pelos pares. O relato enfatiza a experiência comunitária dos pares-multiplicadores do projeto e sua apropriação da avaliação de suas ações preventivas e sociais. Os resultados e a discussão são apresentados numa dupla perspectiva: 1 da seqüência dos questionamentos temáticos que emergiram no percurso da pesquisa-ação participativa no campo; e 2 das práticas de investigação avaliativa desenvolvidas num dado contexto sociocultural e sociopolítico.

Palavras-chave: Investigação comunitária. Avaliação de resultados de ações preventivas. Educação popular em saúde. HIV/AIDS. Amazonas.

\footnotetext{
Enfermeira. School of Nursing, Faculty of Health Sciences, University of Ottawa, Canada. 451, Smyth Rd Ottawa Ontario - K1H $8 \mathrm{M} 5$ hlaperri@uottawa.ca
} 


\section{Introdução}

Este artigo relata a sistematização de uma experiência de pesquisa avaliativa e participativa junto a pares-multiplicadores de projetos de educação em zonas de prostituição no interior da Região Norte do Brasil. O duplo desafio para a consecução dessa pesquisa consistiu em morar próximo ao ambiente de circulação desses pares-multiplicadores e criar aí um espaço de produção coletiva de saberes úteis para esses agentes nas suas atividades de educação para prevenção de doenças sexualmente transmissíveis (DST) e HIV/Aids. A perspectiva dessa pesquisa-ação visava privilegiar uma auto-avaliação que respeitasse o potencial avaliador dos próprios pares-multiplicadores. Compartilhando, nesse contexto sociocultural e sociopolítico, as práticas de enfermagem em DST/HIV/Aids adquiridas anteriormente, as atividades de pesquisa foram conduzidas em zonas de prostituição e bairros populares de um dado município, num raio de cinco a trinta minutos a pé a partir da casa onde a pesquisadora residia. Esta perspectiva de avaliação é qualitativa e enfatizou aspectos não avaliados durante a implantação do projeto inicial, que deu origem ao desdobramento que descreveremos doravante.

Os objetivos específicos da investigação participativa e avaliativa eram: 1 incorporar a participação dos principais atores locais que poderiam ser engajados como pares-multiplicadores na educação da comunidade; 2 explorar uma avaliação empírica dos "impactos globais" das ações preventivas por meio de um processo de auto-avaliação sem as limitações ligadas à produtividade planificada no programa de prevenção de DST/HIV/Aids nas áreas consideradas de alto risco, ligadas à prostituição, e 3 estimular o acúmulo de conhecimentos relacionados às práticas da pesquisa-ação participativa e comunitária.

Os pares-multiplicadores participavam das decisões sobre os temas a serem discutidos e sobre as formas de mobilizar os atores locais, importantes para o desenvolvimento da chamada educação pelos pares. O processo de pesquisa avaliativa foi percebido pelos envolvidos sobretudo como uma recuperação das histórias pessoais e coletivas.

Os laços de confiança estabelecidos nas experiências comunitárias e profissionais realizadas anteriormente, entre 1994 e 2000 (envolvendo a Pastoral Social e da Saúde, Comunidades Eclesiais de Base, a Associação de Mulheres, programas de prevenção à hanseníase e a DST/HIV/Aids), orientaram nossa reinserção nos bairros periféricos e nas áreas de prostituição acima referidos. Descobrimos juntos, pesquisadora e atores sociais engajados, dimensões significativas relativas aos pares-multiplicadores, como os elos de ajuda, mudanças nas trajetórias pessoais e coletivas, transferência dos saberes e também das condições de trabalho educativo nas áreas de alto risco. A perspectiva desta pesquisa participativa e avaliativa era reafirmar a necessidade da apropriação do saber produzido na atividade de "agentes de fronteira" nos programas de saúde pública, vivendo na comunidade. Este artigo descreve o mais objetivamente possível as transformações metodológicas inevitáveis, decorrentes da participação radical na comunidade e, com isso, da partilha estabelecida entre os participantes.

\section{Problematização: a avaliação num contexto de imprevisibilidade, imprecisão e incerteza}

Em 1999, num contexto em que o ecoturismo era estimulado como possibilidade de desenvolvimento do interior da Amazônia brasileira, um membro regional dos programas ligados a DST/ HIV/Aids implantou um projeto inicial de prevenção nas áreas de prostituição, onde alcançava populações das mais marginalizadas, para as quais a prática da prostituição freqüentemente se tornava o único meio de sobrevivência. A chamada educação pelos pares se desenvolvia como uma intervenção específica junto aos trabalhadores do sexo na cidade. Foi nesse período que recebi o convite para acompanhar os pares-multiplicadores e oferecer consultas de enfermagem em DST/HIV/Aids. Esse trabalho consistia na disseminação, entre os trabalhadores do sexo e seus clientes, de informações sobre DST e Aids, e a respeito do uso de preservativo (em 1998, 350 trabalhadores do sexo foram identificados no município, que contava com oitenta mil habitantes). Os pares-multiplicadores faziam intervenções noturnas nos bares flutuantes do porto ou nos pontos de encontro (hotéis, parques públicos, ruas, barcos). O projeto se propunha a: estimular a organização de grupos de defesa dos 
direitos da população-alvo, instruir sobre práticas sexuais sem risco e providenciar a assistência de profissionais da saúde para o tratamento de DST. Financiado por uma fundação estrangeira, com colaboração local e regional, ele teve início com cinco pares-multiplicadores, que eram agentes da comunidade treinados, monitorados e remunerados (Benzaken et al., 2003). Em 2002, as avaliações das pesquisas epidemiológicas e dos questionários evolutivos sobre os comportamentos sexuais, assim como o número crescente de preservativos distribuídos, tinham como objetivo legitimar as ações preventivas (Benzaken et al., 2007, 2003, 2002).

Note-se que havia dificuldades geográficas e socioeconômicas para a produção de pesquisas de avaliação, e mesmo de pesquisas que pudessem valorizar tanto a eficácia prática dos agentes de fronteira quanto a participação de todos os envolvidos. Nos seis anos de residência na região amazônica brasileira, vivendo com populações ribeirinhas em contextos incertos, inseguros, imprevisíveis e violentos, foi bastante difícil obedecer ao rigor científico ocidental, que valoriza sobretudo o distanciamento do pesquisador e a observação isenta. Os métodos de avaliação dos projetos sanitários eram, quase sempre, impostos por agências financiadoras nacionais e internacionais, que descartam a compreensão da influência do contexto sociocultural e sociopolítico na implantação das ações. Composta por grupos comunitários e profissionais da saúde pública, a Comissão Interinstitucional de Controle e Prevenção das DST e da Aids do Estado do Amazonas reconheceu que a aliança precária dos usuários dos serviços de saúde com os profissionais por meio de organizações não governamentais (ONGs) representa uma verdadeira "ditadura dos projetos". Para a Comissão, essas ONGs, financiadas por instituições internacionais, pedem para "ver e medir resultados", em oposição aos resultados "vagos e imprecisos" do ativismo e da intervenção cultural (Comissão Interinstitucional de Controle e Prevenção das DST e da Aids, 2003, p.15). Além do mais, os pesquisadores tornam-se, freqüentemente, os leitores dessa realidade e produzem dela uma tradução que dificilmente é acessível aos participantes locais, retornando a eles sob a forma de resultados abstratos (Latour, 2000). Demo (1999) denuncia a obsessão inovadora do conhecimento moderno, que não raro ignora as desigualdades entre países ricos e pobres quanto à capacidade de produzir e usar um saber próprio. Qual será o discurso de avaliação que permite a expressão da experiência local? Um discurso capaz de alcançar os que estão longe dessa cultura, cujos interesses não estão diretamente envolvidos com a realidade local? O desafio dessa avaliação é reconhecer as distâncias internacionais e nacionais, as descontinuidades culturais entre as regiões centrais e periféricas, as diferenças de tempo na produção local de saberes. Só assim é possível responder prontamente às necessidades básicas de uma comunidade e ao atendimento em saúde para suas populações. Sem esse esforço, dificilmente as condições locais serão entendidas, pois as competências dos pesquisadores e avaliadores, em nível internacional e nacional, é que falarão por elas.

Frente aos desafios geográficos característicos de localidades da região amazônica, é preciso recorrer a registros de outro tipo para formular uma avaliação flexível o suficiente em sua metodologia, considerando a epistemologia que isso implica (Zúñiga, Laperrière, 2006). Como Tanaka e Melo (2004) anotam, "a avaliação tem que ser compreendida no contexto em que é pensada e a partir das perguntas avaliativas a que se quer responder" (p.121). Esse construtivismo na avaliação supõe uma flexibilização dos métodos positivistas de pesquisa (Campbell, 1984).

Nesse tipo de campo, a avaliação que considera os agentes, os quais efetivamente atuam sobre os resultados, foi reconhecida com os trabalhos de Guba e Lincoln (1989) e os diferentes trabalhos que se inspiraram na abordagem da "avaliação da quarta geração" de forma crítica (Zúñiga, 2005; House, Howe, 1999). A noção de "participação" define a ênfase dessas orientações no que tange à avaliação de programas internacionais (Programa das Nações Unidas para o Desenvolvimento e Organização Mundial da Saúde). Mas a legitimidade da participação na América Latina origina-se de autores latinoamericanos, entre os quais Freire (1974), Fals-Borda (1980), Brandão (1985) e Vasconcelos (2002). A perspectiva participativa, decorrendo também da educação popular, está ligada sobretudo aos movimentos populares:

Movimentos sociais de gênero, de etnia, de cultura, de luta pelos direitos humanos, de ação comunitária, de vocação ambientalista, em muitos casos se reconhecem como incorporando, de algum modo, o espírito originário e o ideário das práticas atuais da educação popular. $\mathrm{O}$ 
advento das várias modalidades de pesquisa participante esteve quase sempre vinculado ao ideário e às práticas de educação popular. (Brandão, 2002, p.151 - grifos originais)

\section{Metodologia}

Esta pesquisa avaliativa refere-se à participação radical que, no contexto em que se deu, muito exigiu de todos os envolvidos quanto à capacidade de elaboração e reelaboração dos processos e de sua condução. Trata-se de uma metodologia que valoriza a pesquisa-ação (Vasconcelos, 2002; Reason, 1998) e as significações culturais, valendo-se dos métodos de educação popular desenvolvidos nos movimentos sociais brasileiros (Brandão, 2002). No que diz respeito à contextualização de uma pesquisa (ou groundedness) e aos aprendizados empíricos locais, a noção de imprevisibilidade implicava que os meios iniciais de avaliação poderiam ser modificados no decurso da pesquisa, conforme as situações e oportunidades. Assim, as ferramentas de base utilizadas foram construídas coletivamente pela coalizão quebequense dos órgãos comunitários de luta contra a Aids (Jalbert et al., 1997) e, levadas a diversos movimentos sociais e voluntários, encorajam a participação radical dos agentes de fronteira, valorizando seu potencial avaliador e prescindindo da presença de um avaliador externo ligado ao Estado (Ministério da Saúde e Agência de Saúde Pública).

As entrevistas coletivas dos grupos de apreciação partilhada (GAPs) foram privilegiadas por trabalharem com os pares-multiplicadores. O GAP é uma ferramenta que permite alimentar a reflexão e a autoavaliação coletiva (Jalbert et al., 1997). Não se trata de um trabalho com um grupo focal, pois os participantes decidem sobre a forma e os temas a discutir, tendo início num roteiro sugerido pela ferramenta de auto-avaliação (Figura 1), sobre o qual as entrevistas coletivas vão propondo modificações, sugeridas pelos próprios participantes, no decurso da pesquisa avaliativa. Desse modo, o GAP valorizava as informações que se sobressaíam nos encontros formais e também nos comentários informais entre os participantes. Esse exercício destina-se a levar diferentes agentes à partilha de suas análises sobre o projeto em curso e, assim, contribui para a construção de uma ação efetivamente coletiva, permitido, entre outras coisas, emitir julgamentos sobre as práticas e eventualmente conceber ajustes.

FICHA 5: ROTEIRO PARA ENTREVISTAS COLETIVAS

(Jalbert et al., 1997, tradução nossa)

\section{O GRUPO DOS MULTIPLICADORES}

\section{Apresentação}

Como você se tornou um multiplicador? Como você conheceu o projeto? Descreva as tarefas que você tem realizado nesse trabalho?

\section{A integração ao projeto}

Como se deu sua integração no projeto? Você recebeu uma formação? Que orientação você recebe da equipe?

3. O funcionamento da equipe

Sente-se membro de uma equipe de trabalho? Como funciona essa equipe?

4. A importância dos multiplicadores para o projeto

Como você vê o papel dos multiplicadores no projeto? Sente-se como parte importante dele? Sente-se compromissado ou sente-se usado pelos demais participantes? Você acha que as suas idéias são importantes e valorizadas? Percebe que sua participação na missão do projeto é sempre solicitada, desejada e encorajada? Sente que você tem influência sobre as decisões importantes para a continuidade do projeto?

5. Os contatos com os outros membros

Tem contatos com outros membros do projeto? Esses contatos contribuem para o seu trabalho?

6. A contribuição do projeto

Como você vê a sua contribuição para o projeto? Você pode contribuir para as mudanças que acha necessárias à evolução do projeto? Que ação você desenvolveria para melhorar o projeto?

7. Passos seguintes e avaliação do processo

Figura 1. Roteiro das entrevistas coletivas com os pares-multiplicadores. 
As atividades de entrevista coletiva se desenvolviam sob a forma de perguntas, com uma duração aproximada de $1 \mathrm{~h} 15 \mathrm{~m}$ com cada grupo. Elas foram realizadas em conjunto com as atividades práticas dos projetos de prevenção (reuniões de equipe, visitas às áreas de prostituição e ao local dos projetos de educação pelos pares). O roteiro de base propunha temas como a apresentação do participante, a integração no projeto, o funcionamento da equipe, a importância dos multiplicadores, os contatos com os outros membros, a contribuição para o projeto, entre outros temas significativos para os participantes do GAP (Figura 1). Na medida do possível, os resultados das deliberações foram obtidos por consenso.

Além das formas de animação oriundas das minhas experiências com educação popular brasileira (nas Pastorais Sociais e da Saúde), as ferramentas adaptadas de Epsilon 1 (Jalbert et al., 1997) permitiram a abordagem dos problemas relacionados à percepção do papel que têm em seus projetos, à avaliação que fazem das ações coletivas preventivas e sociais, e aos caminhos de melhoramento que vislumbram. Após cada um dos encontros, uma grade de avaliação dos GAPs servia para resumir os intercâmbios por temas e receber os comentários sobre a experiência. Cada participante ganhava uma cópia dos resultados resumidos do encontro a fim de validar e analisar seu conteúdo com o grupo. Uma pasta plástica foi entregue para guardar esse material. Uma última entrevista coletiva, no fim do processo, permitiu tomar conhecimento das análises e, então, atuar sobre os resultados "finais". Os grupos deveriam chegar a um duplo resultado: a produção de uma síntese da percepção coletiva e uma interrogação sobre as ações futuras que poderiam qualificar "o agir" da organização (Jalbert et al., 1997, p.40).

Para viabilizar a observação participativa, foi importante viver próximo ao local pesquisado, com vistas a conhecer "por dentro" a realidade em foco. Disso decorreu o estabelecimento de relações de confiança que permitiram assistir a um conjunto de acontecimentos sociais aos quais os estrangeiros geralmente não têm acesso. A observação participativa representava um meio para observar e captar as práticas. A imersão no campo orientava as decisões de transformar o roteiro, de visitar os pontos de trabalho dos multiplicadores, de implicar-se nas atividades dos projetos. A vivência anterior e as experiências havidas durante o estudo favoreceram o entendimento do contexto sociocultural e sociopolítico implicados na investigação comunitária. A utilização de um diário auto-etnográfico permitiu descrever a experiência pessoal de pesquisadora, que reflete os pensamentos e as significações culturais como ator social e sujeito nas situações vividas. Com os pares-multiplicadores, além da coleta de dados por GAPs, outras fontes de informaçãa, que não são analisadas neste artigo, completaram o processo de auto-avaliação. Também foram realizadas entrevistas individuais com políticos, administradores municipais, coordenadores regionais e locais, voluntários e usuários dos projetos.

A confiabilidade dos processos e resultados é fortalecida pelo fato de que os participantes da pesquisa também analisaram os dados (Huberman, Miles, 2003). A suposta objetividade científica foi substituída pela confluência de diferentes pontos de vista, com a promoção de um diálogo e uma deliberação coletiva (House, Howe, 1999). Uma consideração ética importante nasceu da necessidade de preservar em sigilo informações potencialmente prejudiciais aos participantes, como sua identidade e a explicitação dos tipos de contatos entre eles. Além disso, para evitar problemas ligados a coerções e manipulação, os participantes tinham o direito de vetar a circulação do material de pesquisa sobre eles. O diálogo, a deliberação e a eventual renegociação com os participantes permaneceram em todo o percurso da pesquisa. O estudo recebeu aprovação dos Comitês de Ética da Fundação Alfredo-da-Matta e da Université de Montréal. A avaliação não foi solicitada nem financiada por instituição de saúde pública. $O$ protocolo foi aceito, de forma que os resultados iam diretamente aos participantes para serem utilizados por eles, que podiam se valer dos relatórios para dar suporte às decisões coletivas frente às agências financiadoras. O trabalho de pesquisa avaliativa era voluntário. O Ministério da Educação quebequense ofereceu uma bolsa para esse estágio internacional, cobrindo as despesas de transporte, viagens entre 0 município pesquisado e a capital do estado do Amazonas e fotocópias dos relatórios. A Comunidade Eclesial de Base com a qual tinha estado compromissada em oportunidade anterior patrocinou as despesas referentes a hospedagem, alimentação e segurança física no local da pesquisa. 


\section{Análise dos resultados}

Os resultados e a discussão são apresentados na seqüência dos questionamentos temáticos emergentes no processo da pesquisa-ação participativa, no seu contexto sociocultural e sociopolítico. Os resultados expõem, assim, os aprendizados havidos no percurso da pesquisa de campo. Eles são acompanhados de excertos de entrevistas que ilustram as análises e interpretações coletivas. Para melhor apresentar o processo das transformações que aconteceram ao longo da pesquisa, no convívio com os participantes na comunidade, esta parte mescla questões de metodologia com resultados e discussão. Essa forma não convencional de apresentação dos dados colhidos pareceu a mais apropriada para comunicar a maneira como os participantes influenciavam e modificavam o processo de pesquisa. Vivia-se um período pré-eleitoral no município pesquisado, e os participantes queriam aproveitar esse espaço de reflexão para otimizar a utilização das informações compartilhadas nos encontros. O tópico anterior, sobre a metodologia de que nos valemos, pontuou os elementos previstos no protocolo antes de entrar no campo. Aqui, pretendemos expor honestamente as questões de imprevisibilidade e registrar as múltiplas direções que vêm tomando as análises na realização concreta dessa pesquisa avaliativa e participativa.

\section{Desenvolvimento da pesquisa-ação participativa em atos: transformar a imprevisibilidade em oportunidade}

A descrição de uma metodologia consiste numa atividade crítica que pretende fazer aparecer uma justificação das escolhas num processo de pesquisa. Nesta pesquisa-ação participativa, as considerações importantes foram: 1 o desempenho de uma avaliação em contextos situados nos limites do controle por parte da pesquisadora; 2 o confronto com uma realidade complexa e uma ampla variedade de atores; 3 os riscos de perigo sociopolítico; e 4 a situação social que torna difícil as previsões de planos estruturados com rigidez. Os métodos escolhidos deviam levar em conta esse conjunto de variáveis. Nesse sentido, o termo "imprevisibilidade" foi usado para legitimar uma perspectiva que tentou otimizar as oportunidades de acesso a informações úteis para nós (os pares-multiplicadores e a pesquisadora) e a atualização desses saberes nos contextos concretos de práticas preventivas. Enfim, a noção de imprevisibilidade permitiu contemplar o impacto de variáveis contextuais não controláveis na pesquisa avaliativa (ingerências políticas; ausência de recursos indispensáveis, como eletricidade e água; vulnerabilidade a crises climáticas, criminalidade e corrupção).

A imprevisibilidade na aplicação do método inicialmente definido foi também acentuada pela participação de pessoas habitualmente excluídas desses fóruns, desacostumadas a terem suas opiniões contempladas, como no caso dos programas sanitários - uma exclusão devida a suas formas de vida (em bairros distantes ou comunidades ribeirinhas isoladas, sendo uma região de riscos advindos de inundação) e atividades de trabalho (em geral, trabalhadores do sexo, traficantes e detentos). A cooperação estabelecida significava que os participantes e eu confiávamos em nosso potencial de melhoramento rápido das condições concretas de vida e trabalho (desde o primeiro dia) e, além disso, os pares-multiplicadores viviam um período atormentado entre a urgência de agir e a necessidade de refletir sobre o que fazer. Além disso, ainda que fosse possível propor um calendário e um plano de desenvolvimento da pesquisa avaliativa, os limites de infra-estrutura da localidade exigiriam uma lógica mais prática, na qual o método tentou se inserir da maneira mais natural possível. A imprevisibilidade tinha apoio inclusive no consenso entre os participantes de que a pesquisa comunitária teria um impacto positivo não somente na produção de novos conhecimentos acadêmicos, mas também na qualidade das condições de trabalho dos pares-multiplicadores.

Para promover essa auto-avaliação entre colegas, os pares-multiplicadores, que eram trabalhadores do sexo antigos ou novos, fui morar numa casa num bairro central, ao qual todos tinham fácil acesso. Desse modo, os participantes podiam me observar na relação com os vizinhos e em minhas atividades cotidianas no comércio, nos parques, nos pontos de trabalhos do projeto, nas celebrações e festas, nas casas, nas regiões portuárias, nos centros de saúde e nos espaços rurais próximos ao município. Como se vê, não se tratava exatamente de uma abordagem etnográfica tradicional, pois estava sediada em minha moradia e cultivava relações com vizinhos e colegas desde 1994. O contexto da auto-avaliação 
era, então, um espaço aberto não só aos participantes da pesquisa, mas também a eventuais acompanhantes, como os vizinhos e outros moradores da comunidade. Nas entrevistas individuais ou coletivas, eu era chamada por meu nome ou por vizinha, amiga, colega e enfermeira.

Essa participação exigiu negociações, pois, logo no início, a coordenação regional dos programas já em curso questionava: "O que as meninas [pares-multiplicadores] terão em troca por sua participação, sua contribuição para o projeto de pesquisa? Troca faz parte da prostituição" (excerto da discussão com a coordenação local e regional, 2004). Além disso, a coordenação local considerava que o projeto de pesquisa estava chegando a um momento estratégico em que deveríamos resgatar toda sua história para Ihe dar novo impulso. Considerava-se importante incluir dois outros projetos de educação sobre DST/ HIV/Aids pelos pares-multiplicadores do município. E, então, eles foram incluídos nas atividades de investigação comunitária: um projeto voltado aos homens que fazem sexo com homens (HFSH) e um outro que se dirige mais especificamente aos jovens de bairros periféricos. As mudanças de trajetória e de comportamento dos participantes foram enunciadas como as principais preocupações da coordenação local: "Será que os usuários deixam a prostituição após o contato com os projetos de prevenção? Sobretudo, eu queria dar espaço aos pares-multiplicadores para que eles digam o que importa para eles" (excerto da discussão com coordenação local e regional, 2004).

Após uma semana de integração nesse município, três grupos de apreciação partilhada (GAPs) foram constituídos, respectivamente, por pares-multiplicadores dos projetos voltados para os trabalhadores do sexo $(n=5)$, dos HFSH $(n=7)$ e dos jovens de bairros periféricos $(n=5)$, com um total de 17 participantes. Em vez de realizar uma única entrevista coletiva, decidiu-se estender o roteiro por um período de tempo determinado com vistas a otimizar o processo de reflexão por meio das práticas cotidianas. Assim, do dia 4 de março até 16 de abril de 2004, seis entrevistas coletivas semanais por grupo permitiram acompanhar as temáticas do roteiro durante os períodos habituais de reunião da equipe (18 reuniões com presença de $75 \%$ dos pares-multiplicadores implicados nos projetos). Ao longo do processo, os encontros passaram a ser iniciados com o retorno, aos participantes, do conteúdo das entrevistas coletivas anteriores. A deliberação e a negociação dos dados coletados exigiam flexibilização do método de grupo focal. Encontros complementares foram necessários para rever os objetivos da pesquisa e avaliar nossa compreensão comum das conseqüências da divulgação futura das informações colhidas. A convivência cotidiana no campo sugere que a educação para prevenção de DST/HIV/Aids pelos pares implica uma avaliação dinâmica com os trabalhadores do sexo, considerando não somente a implantação, mas também as mudanças que se produzem no método no decurso dos trabalhos. No nosso caso, a ancoragem na dinâmica local certamente favoreceu a eleição de critérios que selecionaram pessoas de fato empenhadas no êxito do projeto.

\section{A pesquisa-ação participativa para os participantes}

Demo (2001) afirma que a arte do processo de investigação participativa é tratar sabiamente das preocupações de auto-sustentação e de sobrevivência, como sendo consolidação da cidadania. Se a participação for radical e honesta, é necessária uma apropriação local das decisões metodológicas da pesquisa avaliativa. É preciso que partilhemos (pesquisadores e pares-multiplicadores) a apropriação dos objetivos, dos procedimentos e dos modos de análise: todos são necessários para que haja uma apropriação dos resultados: "Para entender como alguém lê, é necessário saber como são seus olhos e qual é sua visão de mundo" (Boff, 2003, p.9). Este excerto ilustra a maneira como os participantes entendiam o processo de relatar as atas das entrevistas coletivas nas reuniões:

\footnotetext{
Um inicia com uma idéia; um outro a acrescenta. Enfim, este processo termina com um texto coletivo que tem sentido para nós. Isto justifica a importância, numa próxima reunião, de voltar sobre os temas discutidos no encontro anterior. Esta é uma forma de consenso sobre o que é importante para nosso projeto, para nos propulsar em direção à ação. É uma forma de saber construído conjuntamente, que é a nossa imagem, com suas imperfeições, mas ligado à nossa realidade concreta, ao nosso trabalho, às nossas práticas do cotidiano. (Transcrição de um GAP, 18-03-2004)
} 
O método participativo previsto tinha uma estrutura inicial equivalente a $25 \%$ do trabalho (roteiro de base e protocolo de pesquisa). Demandava uma consciência coletiva de que a participação exigiria um significado co-construído, isto é, de que todos deveriam estar de acordo sobre o que tentávamos construir conjuntamente. Conseqüentemente, a participação era uma negociação cultural. A cooperação na investigação participativa supunha uma lógica de participação coletiva, de inclusão das opiniões de participantes habitualmente excluídos das avaliações e das gestões municipais (em geral, trabalhadores subalternos, jovens, trabalhadores do sexo, moradores de invasões ou parques públicos). Assim, a perspectiva da avaliação participativa radical precisava de uma comunicação aberta que não se dava habitualmente nos contextos de poder político, social e econômico. Vivíamos num contexto em que, apesar de quaisquer esforços em contrário, as informações escapariam do grupo e se disseminariam. Mencionou-se, certa vez, que nos gruops havia participantes ligados à política partidária. Por isso foi de suma importância discutir abertamente essa situação durante as entrevistas coletivas, pois estávamos em período pré-eleitoral e era imprescindível uma definição coletiva de confidencialidade e ética:

Certo, existem histórias mais pessoais, anedotas, situações vividas por uma só participante. A apresentação destes trechos de histórias são inestimáveis para o grupo. Estas situações ou estes eventos escolhidos para serem escritos no relatório estão lá para dar uma imagem dos temas escolhidos e discutidos em grupo. Para preservar a confidencialidade dos atores, estas histórias são apresentadas de forma impessoal e sem nome. Nós sabemos quem são os atores de tal história falada no encontro anterior, nós nos relembramos, mas devemos o mais possível tentar preservar o anonimato para permitir que estes participantes possam continuar a se expressar espontânea e livremente durante os encontros. É certo que os participantes podem retirar trechos de histórias pessoais que não querem que apareçam no relatório oficial. (Transcrição de um GAP, 18-03-2004)

As modificações no protocolo previsto podiam ser percebidas como imprevisibilidades indesejáveis do ponto de vista da instituição de pesquisa e da administração de saúde pública. Afinal, é bastante possível que um estrangeiro não saiba decodificar os fatores de variabilidade contingente desse pequeno município longínquo e, então, os veja como obstáculos intransponíveis. Minha experiência no campo durante o período pré-eleitoral sugeria que responder às necessidades de ajustes para contornar os obstáculos aparentemente sem saída implicava uma compreensão evolutiva das preocupações dos participantes e uma capacidade de encaminhar as transformações possíveis sem expor a riscos as pessoas envolvidas (refiro-me a problemas como falta de água e eletricidade, ameaças aos participantes por gangues de rua, à cooptação para campanhas eleitorais e congêneres). Creio que temos de aceitar a premissa de que a ciência do povo é o conhecimento prático, vital, empírico, que o permitiu sobreviver, interpretar, criar, produzir e trabalhar por séculos, e tem sua própria racionalidade e sua própria estrutura de causalidade (Fals-Borda, 1980).

Em determinado momento dos intercâmbios, alguns participantes manifestaram o desejo de entrevista individual em forma de narração de vida ou poema. Eles contavam a história de sua infância e dos primeiros contatos com o projeto inicial de educação pelos pares. Tratava-se de uma forma de dar o testemunho de experiências com a intenção de ajudar outras pessoas vivendo situações semelhantes. Para os pares-multiplicadores, dos quais alguns tiveram transformada sua trajetória pessoal no contato com o projeto, o trabalho formal de educador da saúde era percebido como uma oportunidade de inclusão social. Muitos ilustravam essa transformação como a passagem de um estado "de animal a humano", no qual se pode "ser chamado de Senhor [Mr.]" e "ser cumprimentado por policiais" (transcrição de excertos de entrevista individual, março 2004). Essas entrevistas individuais ("em particular", como referiam os participantes) não estavam previstas no método inicialmente elaborado, mas vieram acrescentar profundidade às discussões coletivas sobre as mudanças pessoais atribuídas ao projeto inicial com trabalhadores do sexo. Alguns participantes multiplicadores recuperaram o resumo do "relato de vida" deles como material educativo no contato com os pares: 
Foi ali que teve o primeiro contato com o projeto, no cais [...] Ouviu uma palestra e nesta o multiplicador falou sobre DST e Aids. Admirou-se de ver como um homossexual podia dar palestra, fazer este trabalho, fora das áreas tradicionais de trabalho homossexual, como os cabeleireiros. Achava que não tinha esperança para o trabalho de um homossexual. (Excerto de um relato de vida construído numa entrevista individual, abril 2004)

A convivência cotidiana no campo e as experiências anteriores de prática comunitária de enfermagem no município ofereceram uma proximidade peculiar com os participantes. Os laços de confiança e a restituição sistemática das informações recolhidas foram os pontos-chave para a concretização dessa participação. Podíamos facilmente fazer comentários, recortar pedaços, discutir a forma de divulgação, até conversar sobre conteúdos pessoais mais íntimos, tanto dentro da casa que servia de ponto de encontro, como em espaços não institucionais (nas lanchonetes, nos bares ou nos parques, na rua etc.).

\section{Produção e transmissão rápida dos saberes para melhoramento concreto das condições de trabalho dos pares-multiplicadores}

Durante o percurso dos encontros, construímos, juntos, novas informações que serviam imediatamente para reorientar as atividades nos pontos de trabalho. Por exemplo, houve uma ocasião em que discutimos sobre a diminuição de trabalhadoras do sexo nas consultas de DST/Aids na sede do projeto. "Pensa-se que seria porque o atendimento custa muito tempo e, às vezes, os donos [cafetões] não vão deixar as mulheres irem para consulta, uns outros sim. [...] Mas tem que saber realmente o que está acontecendo..." (transcrição de um GAP, 7-04-2004). Propôs-se, então, reunir pequenos grupos de mulheres e conversar com elas, saber melhor o que pensavam sobre as consultas. Num outro momento, discutiu-se o valor da não-divulgação de certas informações para permitir aos participantes falarem livremente durante os encontros.

Esses novos procedimentos desenvolvidos no contexto da investigação decorreram das preocupações com as práticas educativas junto aos trabalhadores do sexo, pois

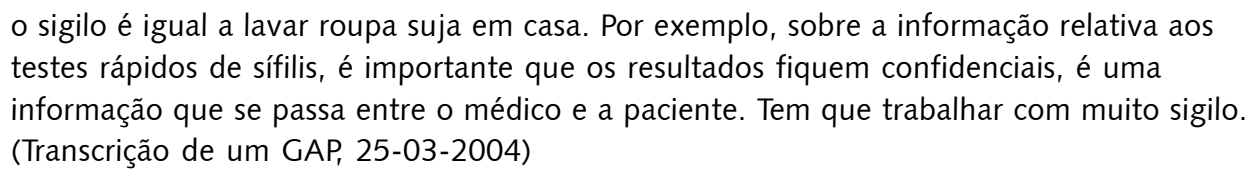

As observações permitiram constatar que, durante suas conversas informais, os pares-multiplicadores compartilhavam suas aprendizagens, seus conhecimentos, suas reflexões sobre a maneira de abordar os trabalhadores do sexo ou os donos de bar, as dificuldades encontradas nos flutuantes e a organização de nova atividade no município.

Desde o início do processo, vários pares-multiplicadores manifestaram preocupações frente à descontinuidade dos serviços de atendimento a esse grupo. O fato de "saber para onde elas vão" e "saber como se organizar" foi apontado várias vezes como relevante (transcrição de um GAP, 4-032004). Foi importante, então, observar indicadores tangíveis no processo de auto-avaliação dos projetos. Desse modo, as entrevistas coletivas levaram em consideração a lucidez dos pares-multiplicadores locais quanto às possibilidades reais de transformação social no município. Eles sabiam muito mais sobre o que podia realmente ser concretizado e o que ultrapassava as possibilidades de mobilização coletiva dos trabalhadores do sexo na cultura local. E, ao longo do processo de auto-avaliação, os paresmultiplicadores dos três projetos acabaram por se unir para iniciar visitas sanitárias nas duas prisões municipais. Eles queriam oferecer atendimento médico, testes rápidos de sífilis e palestras educativas às mulheres detentas. No final do estudo, em junho de 2004, essas atividades foram incorporadas ao cronograma dos projetos de prevenção DST/HIV/AIDS. O processo de auto-avaliação, com seu potencial de mobilização, tem "gerado práticas e saberes imprevisíveis" (Vasconcelos, 2002, p.114). 


\section{Percepção do processo de auto-avaliação: resgatar a história coletiva}

Neste tópico, tratamos de uma narrativa que apresenta o olhar dos pares-multiplicadores sobre o trabalho de educação de que participam. Um texto construído coletivamente expõe os elementos considerados essenciais. Após deliberação em grupos, sem minha presença, eles escolheram excertos dos encontros em GAPs que consideraram significativos para divulgação ao público externo. A seguir, alguns dos excertos do texto coletivo enviado para o jornal interno da coalizão quebequense de luta contra a Aids:

Nós, multiplicadores, saímos de casa às $20 \mathrm{~h} 00$ na quinta-feira e vamos até o ponto de encontro que fica localizado na praça frente ao cais do porto. [...] Algumas [trabalhadoras do sexo] contam o que tem acontecido no seu dia-a-dia e de repente nós viramos confidentes ali mesmo na mesa de um bar. Recebemos confidências como, por exemplo, a história aonde elas falam sobre a filha que foi morta por um marginal [...]. (Transcrição de um GAP, 14-04-2004)

Trabalhar junto com a carência. Os multiplicadores têm que conquistar estas pessoas... vão dar carinho, vão trabalhar com estas carências - claro que não é chantagem emocional. [...] contato é primordial - pois os multiplicadores não são robôs distribuidores de camisinhas e informação. (Transcrição de um GAP, 25-04-2004)

Trabalho de conjunto. Outro acrescenta que todo mundo vai junto no trabalho, não trabalham sozinhos... Deste jeito, cada um coloca sua idéia, mostra uma coisa para os outros. [...] O projeto tem como meta a Educação pelos pares, então, vamos dois ou três (formando uma equipe). Em relação aos preconceitos, tem que ir juntos, para enfrentar as pessoas, dar as palestras nas escolas, mostrar slides... (Transcrição de um GAP, 18-03-2004)

Discutimos também a importância dos valores humanos (cordialidade, paz, crescimento, coragem, esperança, benevolência), de um trabalho coletivo e de parceria, das preocupações com a transmissão dos saberes que adquiríamos no percurso das ações educativas. Vários pares-multiplicadores expressaram preocupação com a percepção da população em geral frente ao compromisso deles com trabalhadores do sexo, e desejavam que o trabalho de pares-multiplicadores fosse reconhecido como contribuição social para todo o município.

$\mathrm{Na}$ avaliação do método dos GAPs, sobressaiu a dimensão de recuperação da história coletiva. "Assim, foi deliberada esta questão do retorno das informações, das palavras, dos temas através dos relatórios do GAP e das discussões sobre isto em cada reunião. No final, parece que é o único método de trabalho para auto-reflexão pessoal e coletiva" (transcrição de um GAP, 10-03-2004). Em um dos GAPs, mencionou-se especificamente que o retorno "das palavras" pode ser vivido como uma certa autodiscriminação. "Foi explicado que ler no papel a 'história' que foi dita verbalmente provoca uma certa discriminação de si mesmo, pois a pessoa vive numa sociedade que a discrimina e a marginaliza" (transcrição de um GAP, 25-03-2004). A maioria dos participantes mencionou que os encontros ajudavam a relembrar sua história no projeto de prevenção a DST/HIV/Aids. E, juntos, também relembramos as dificuldades para chegar até hoje, a origem dos projetos voltados aos homossexuais e aos adolescentes de bairros periféricos com base na experiência inicial nas zonas de prostituição do município. Para Brandão (1985), isso significa "aprender a reescrever a história a partir de sua história" (p.111).

O conteúdo das entrevistas coletivas foi retornado, primeiro, aos respectivos GAPs, sob forma de minutas das temáticas discutidas e analisadas coletivamente durante os encontros. Os três grupos participantes receberam um relatório para que pudessem dialogar com os resultados e lhes dar as feições finais. Eles foram convidados a usar esses dados para divulgação nos congressos nacionais ou nas negociações com agências financiadoras. Com o retorno sistemático das informações construídas nos GAPs, o processo gerou uma constante reflexão sobre situações emergentes e urgentes no município. No momento da avaliação final, os participantes descreveram a experiência como um "fortalecimento 
como pessoa e como projeto", "um despertar" que "aumentou a auto-estima", "deu uma renovada", uma "vira-volta", permitiu "mudar o cotidiano", "um pensar em incorporar outras atividades (sobre uso de drogas injetáveis, visitas às penitenciárias, encontros em novos pontos das trabalhadores do sexo etc.)" (transcrição de um GAP, 28-05-2004). A re-apropriação do discurso de nossas ações suscitou uma "re-apropriação dos atos" (Mendel, 1998) e a criação de um novo "agir", tanto no processo da pesquisa avaliativa quanto nas práticas de educação pelos pares.

\section{Considerações finais}

A pesquisa avaliativa teve início no campo no momento em que os pares-multiplicadores se questionavam sobre a auto-sustentação dos projetos municipais de prevenção em curso. Sem ajustes ou adaptações dos procedimentos metodológicos inicialmente previstos, os resultados da pesquisa teriam sido distantes das preocupações concretas dos participantes. A análise da experiência mostra que existe um processo evolutivo tanto nas práticas de educação pelos pares quanto na pesquisa. A percepção do dinamismo das transformações durante esse processo não teria sido possível por meio de uma abordagem transversal. Foi pesquisa avaliativa com inserção no campo que permitiu a observação dessas mudanças. Os esforços de compreensão foram dirigidos para esse dinamismo interno, mais do que para o acúmulo de dados possivelmente inúteis para os pares-multiplicadores.

O confronto cotidiano com a realidade pesquisada ressaltou formas de inércia, oposições e distorções nas relações sociais e políticas constitutivas dos projetos de prevenção levados a cabo pelos pares. Diante disso, um participante notou que a reflexão fomentada pelos GAPs permitiu "desatar os nós" que freavam as atividades dos projetos. A pesquisa-ação participativa suscitou a revelação de dimensões que não eram necessariamente levadas em consideração nas avaliações quantitativas anteriores. Os intercâmbios deram relevo, entre outras coisas, a dimensões da realidade, como a territorialidade dos grupos nos bairros periféricos, que são difíceis de alcançar quando os objetivos preestabelecidos ignoram as características variáveis do contexto local. Já que essas dimensões da realidade não encontram indicadores mensuráveis e reconhecidos cientificamente, permitindo sua expressão pública, muitas atividades realizadas pelos agentes de fronteira não são ouvidas ou são censuradas. É o caso das ações de solidariedade, das formas originais de estabelecimento dos elos de confiança, que permitem a superação dos obstáculos de um contexto caracterizado por alto nível de periculosidade.

Como registrou um membro da coordenação do programa, para avaliar as ações de saúde no contexto amazônico, de saída é preciso levar em consideração as previsões das cheias e das vazantes do rio, já que as distâncias são percorridas por via fluvial:

\footnotetext{
O meio geográfico é propício para o desenvolvimento de uma inteligência prática em ligação com uma realidade palpável e aos problemas do cotidiano da sobrevivência. As aprendizagens desta forma de pensamento concreto são criadas a partir das analogias com a natureza, as comparações com situações similares, experiências vividas coletivamente ou individualmente. (Transcrição de entrevista individual, abril 2004)
}

Nosso resgate histórico da implantação do projeto inicial de educação pelos pares nos meios de prostituição sugere um processo de transferência das aprendizagens coletivas realizadas pelos paresmultiplicadores, que foram utilizadas na criação de dois outros projetos de prevenção no município. Os aprendizados relativos às experiências de participação e de auto-avaliação com base no projeto inicial, levado a cabo em 1999 com trabalhadores do sexo, foram inseridos nas atividades dos novos projetos de 2003 e 2004. Contemplar tais dimensões de participação contribuiu para transformar trajetórias pessoais e mesmo coletivas (como é o caso, particularmente, da comunidade homossexual). Parece, então, de suma importância que se leve em consideração que essas mudanças de trajetória e as aprendizagens práticas dos participantes (inclusive da pesquisadora) continuam no tempo. O exemplo que os pares-multiplicadores projetam em seus bairros, junto a suas famílias e a seus próximos faz desses atores locais agentes de transformação sanitária e social fora da rede institucional de saúde. 
Por fim, pode-se dizer que a maior dificuldade desta pesquisa é a generalização da experiência da perspectiva de participação popular (Vasconcelos, 2002). Firestone (1990) argumenta que, na elaboração de uma investigação, é preciso refletir sobre três critérios: 1 a generalização, 2 a precisão e o controle das medidas, e 3 o realismo existencial. Mas esses três critérios não podem ser elaborados e postos em prática simultaneamente, o que coloca o pesquisador num dilema. A ênfase de um critério provoca a obnubilação dos outros; assim, a etnografia clássica é extremamente acurada no que diz respeito ao realismo existencial, porém apresenta resultados com menor potencial de generalização e precisão. De fato, não há um método melhor do que outro: tudo depende do enfoque de análise. No nosso caso, a avaliação era valorizada como possibilidade de aprendizagem (Kushner, 2000), era uma tentativa de interface entre saberes populares, sociais e profissionais na produção de conhecimentos sobre prevenção de DST/HIV/Aids, na qual a comunidade se tornou avaliativa. Neste estudo, propus avaliar os projetos em curso, de forma qualitativa e participativa, para melhor entender uma realidade complexa dando voz a quem, em geral, é "abafado" nas avaliações externas.

\section{Agradecimentos}

Agradeço aos pares-multiplicadores dos projetos referidos e à Dra. Adele Schwartz Benzaken, coordenadora do Setor DST/HIV/Aids da Fundação Alfredo-da-Matta, pelo convite para retornar ao interior do Amazonas a fim de desenvolver esta pesquisa; assim como pela qualidade da sua abordagem na prevenção de DST/ HIV/Aids com trabalhadores do sexo. Agradeço, também, ao professor Ricardo Zúñiga, do Serviço Social da Universidade de Montreal, que me orientou com seus conselhos sobre avaliação comunitária e metodologia participativa.

\section{Referências}

BENZAKEN, A.S. et al. Intervenção de base comunitária para a prevenção das DST/Aids na região amazônica, Brasil. Rev Saúde Pública, n. 41 (Supl.2), p.118-26, 2007.

BENZAKEN, A.S. et al. Risk perception for STD and behaviour changes in sex professionals of Manacapuru municipality. DST J. Bras. Doenças Sex. Transm., v.15, n.2, p.9-14, 2003.

BENZAKEN, A.S. et al. Baixa prevalencia de DST en profesionales del sexo en un municipio del interior de Amazonas. DST J. Bras. Doenças Sex. Transm., v.14, n.4, p.9-19, 2002.

BOFF, L. A águia e a galinha: uma metáfora da condição humana. 4.ed. Petrópolis: Vozes, 2003.

BRANDÃO, C.R. A educação popular na escola cidadã. Petrópolis: Vozes, 2002.

Pesquisa participante. São Paulo: Brasiliense, 1985. 
CAMPBELL, D.T. Can we be scientific in applied social science? In: OVERMAN, E.S. (Org.). Methodology and epistemology for social science. Chicago: The University of Chicago Press, 1989. p.315-35.

COMISSÃO INTERINSTITUCIONAL DE CONTROLE E PREVENÇÃO DAS DOENÇAS SEXUALMENTE TRANSMISSÍVEIS E AIDS. Plano Interinstitucional das DST e Aids no Estado do Amazonas. 2003. Disponível em: <http://www.aids.gov.br>. Acesso em: 14 ago. 2005.

DEMO, P. Conhecimento moderno: sobre ética e intervenção do conhecimento. Petrópolis: Vozes, 1999.

FALS BORDA, O. La ciencia y el pueblo: nuevas reflexiones, 1980. In: SALAZAR, M.C. (Org.). La investigación-acción participativa: inicios y desarrollos. Buenos Aires: Humanitas, 1992. p.63-84.

FIRESTONE, W.A. Accommodation: toward a paradigm praxis dialectic. In: GUBA, E.G. (Org.). The paradigm dialog. Newbury Park: Sage, 1990. p.105-24.

FREIRE, P. Pédagogie des opprimés. Paris: Maspero, 1974.

GUBA, E.G.; LINCOLN, Y.S. Fourth generation evaluation. Newbury Park: Sage, 1989. HOUSE, E.R.; HOWE, K.R. Values in evaluation and social research. Thousand Oaks: Sage, 1999.

HUBERMAN, M.B.; MILES, A.M. Analyse des données qualitatives. 2.ed. Bruxelles: De Boeck, 2003.

JALBERT, Y.; PINAULT, L.; RENAUD, G.; ZUNIGA, R. Epsilon: guide d'auto-évaluation des organismes communautaires. Montréal: Coalition des organismes de lutte contre le Sida (COCQ-Sida), 1997.

KUSHNER, S. Personalizing evaluation. London: Sage, 2000.

LATOUR, B. Ciência em ação. São Paulo: Ed. UNESP, 2000.

MENDEL, G. L'acte est une aventure: du sujet métaphysique au sujet de l'acte pouvoir. Paris: La découverte, 1998.

REASON, P. Three approaches to participative inquiry. In: DENZIN, N.K.; LINCOLN, Y.S. (Orgs.). Handbook of qualitative research. Thousand Oaks: Sage, 1998. p.324-39.

TANAKA, Y.; MELO, C. Reflexões sobre a avaliação em serviços de saúde e a adoção das abordagens qualitativa e quantitativa. In: BOSI, M.L.M.; MERCADO, F.J. (Orgs.). Pesquisa qualitativa de serviços de saúde. Petrópolis: Vozes, 2004. p.121-36.

VASCONCELOS, E.M. Educação Popular e Pesquisa-Ação como Instrumentos de Reorientação da Prática Médica. In: GONSALVES, E.P. (Org.). Educação e grupos populares: temas (re)correntes. Campinas: Alinea, 2002. p.99-116.

ZÚÑIGA, R. La evaluación en la acción social: autonomías y solidaridades. 2005. Disponível em: <http://www.homepage.mac.com/ricardo.b.Zúñiga>. Acesso em: 15 set. 2005.

ZÚÑIGA, R.; LAPERRIÈRE, H. A avaliação comunitária: conflitos verticais e ambigüidades metodológicas. In: BOSI, M.L.M.; MERCADO, F.J. (Orgs.). Avaliação de programas e serviços de saúde: enfoques emergentes. Petrópolis: Vozes, 2006. p.118-44. 
LAPERRIÈRE, H. El caso de una comunidad evaluativa emergente: reapropiación por los pares-multiplicadores de la apreciación de sus propias acciones preventivas y sociales contra las ITS/VIH/Sida en Amazonas, Brasil. Interface - Comunic., Saúde, Educ., v.12, n.26, p.527-40, jul./set. 2008.

Este artículo relata la sistematización de una experiencia de investigación evaluativa y participativa de un proyecto de prevención de las ITS/VIH/Sida implantado en las zonas de prostitución de un municipio del interior del estado de Amazonas, Brasil. La perspectiva de evaluación cualitativa ha enfatizado aspectos que no fueron considerados en la implantación del proyecto inicial, referentes a la construcción de los significados colectivos directamente unidos a la implantación de la educación por los pares. El relato enfatiza a experiencia comunitaria de los pares-multiplicadores del proyecto y su reapropiación de la evaluación de sus acciones preventivas y sociales. Los resultados y la discusión se presentan en un doble prisma: 1 de la secuencia de los cuestionamientos temáticos que emergieron en el campo, y 2 de las prácticas de investigación evaluativa desarolladas en un determinado contexto sociocultural y sociopolítico.

Palabras clave: Investigación comunitaria. Evaluación de resultados de acciones preventivas. Educación popular en salud. VIH/Sida. Amazonas.

Recebido em 08/05/06. Aprovado em 28/08/07. 